\title{
ASSOCIATION OF SUBCLINICAL HYPOTHYROIDISM WITH METABOLIC SYNDROME: A CROSS-SECTIONAL STUDY
}

\section{Medicine}

Dr. Rajesh Kumar M.D. (Medicine), Ph.D. (Medicine), Assistant Professor, Department of Medicine, Jha Darbhanga Medical College and Hospital, Laheriasarai, Bihar.

Dr. Sanjay Nath Jha*

Dr. Vinayanand Jha
M.D. (Medicine), Ph.D. (Medicine), Assistant Professor, Department of Medicine, Darbhanga Medical College and Hospital, Laheriasarai, Bihar. *Corresponding Author

\begin{tabular}{ll}
\hline $\begin{array}{l}\text { Dr. Krishna } \\
\text { Kumar Jha }\end{array}$ & $\begin{array}{l}\text { M.D. (Medicine), Associate Professor, Department of Medicine, Darbhanga Medical } \\
\text { College and Hospital, Laheriasarai, Bihar. }\end{array}$ \\
\hline Dr. Debarshi Jana & $\begin{array}{l}\text { Young Scientist (DST), Institute of Post-Graduate Medical Education and Research, } \\
\text { A.J.C. Bose Road, Kolkata-700020, West Bengal, India }\end{array}$ \\
\hline
\end{tabular}

DTM \& H, M.D. (Medicine), Ph.D. (Medicine), Associate Professor, Department of Medicine, Darbhanga Medical College and Hospital, Laheriasarai, Bihar.

\begin{abstract}
Objective: Metabolic syndrome (MetS) and subclinical hypothyroidism (SCH) both are known to have adverse cardiovascular outcomes. Available studies have shown variable results on the association of SCH with MetS as well as individual components of MetS. We aimed to study the association of SCH with MetS and its individual components of MetS.

Material and Methods: This cross-sectional study was carried out in individuals volunteered for health checkup at Department of Medicine, Darbhanga Medical College and Hospital, Laheriasarai, Bihar. About 60 cases with MetS and 120 controls without having MetS were recruited. Demographic data such as history of diabetes mellitus, hypertension, dyslipidemia, blood pressure (BP), waist circumference and serum T3, serum $\mathrm{T} 4$, thyroid stimulating hormone, fasting blood sugar, fasting lipid profile, and hemoglobin A1c were collected and statistically analyzed. Statistical analysis was done by using SPSS sav software packages. Chi-square test was used for the comparison of qualitative data.

Results: SCH was present in $52(28.9 \%)$ among 180 study participants. SCH was present in 35 (58.33\%) participants having MetS and in 17 $(14.16 \%)$ of controls. There was a strong association between SCH and MetS ( $<<0.001)$. Significant association of SCH with diastolic BP $(\mathrm{p}=0.017)$ and with central obesity $(\mathrm{p}=0.004)$ was observed but not with high-density lipoprotein, triglyceride, hyperglycemia, systolic BP, total cholesterol, and low-density lipoprotein.

Conclusion: We observed a strong association of $\mathrm{SCH}$ with MetS. We also observed significant association of SCH with diastolic BP and with obesity. The finding of this study indicates the need to screen individuals with MetS for SCH.
\end{abstract}

\section{KEYWORDS}

Central obesity, Diastolic blood pressure, Hypertriglyceridemia, Hypertension, Cardiovascular morbidity, Inflammation, Insulin resistance, Low-density lipoprotein, High-density lipoprotein.

\section{INTRODUCTION}

Prevalence of metabolic syndrome (MetS) has increased significantly in last few decades.Central obesity, hypertriglyceridemia, hypertension, hyperglycemia, and low value of high-density lipoprotein (HDL) constitute important components of MetS. The relationship among insulin resistance, MetS, and cardiovascular (CV) morbidity and mortality has now been well established. Thyroid hormone disorders are also known to have adverse CV outcomes. Subclinical hypothyroidism ( $\mathrm{SCH})$ is considered early stage of hypothyroidism when level of T3 and T4 are normal but thyroid stimulating hormone (TSH) is high in the blood. SCH is no more considered benign condition; recently, various studies have demonstrated the relationship of $\mathrm{SCH}$ with increased $\mathrm{CV}$ morbidity and mortality. While the role of inflammation is been established in pathogenesis of MetS; few studies have also shown the association of $\mathrm{SCH}$ and inflammation. Considering all these observations, it appears that both MetS and $\mathrm{SCH}$ have common soil of origin, i.e., inflammation and common end point, i.e., increased CV morbidity and mortality. Studies have shown the association of SCH with insulin resistance which is considered as one of the very important pathogenetic mechanisms in patients with MetS. Thyroid hormones and SCH are shown to be associated with individual components of MetS mainly obesity and dyslipidemia. With various associations of $\mathrm{SCH}$ with pathophysiological aspect and components of MetS observed in these studies; there is also a possibility of association of SCH with MetS. Few studies in different parts of the world have demonstrated this association. At the same time, in few studies, this relationship was not established. Since the available studies show conflicting causal relationship between these two common conditions, need was felt for carrying out research to establish relationship between them. We aimed to study the association between $\mathrm{SCH}$ and MetS in healthy individuals.

\section{MATERIALAND METHODS}

This was a cross-sectional study. This study was done at Department of Medicine, Darbhanga Medical College and Hospital, Laheriasarai, Bihar between July 2019 and June 2020. Individuals of more than 18 years, coming for voluntary health check-up program, were recruited for the study. About Sixty individuals with MetS and 120 individuals of age matched control were included in this study. Criteria to select MetS participants were according to the International Diabetes Federation (IDF) definition. According to IDF definition, waist circumference (WC) of $\geq 90 \mathrm{~cm}$ in men and $\geq 80 \mathrm{~cm}$ in women is considered as central obesity; which is threshold considered for South Asian population. Individuals with liver disorders, renal disorders, congestive cardiac failure, pregnant women, patients on oral contraceptive pills, or medications that alter the thyroid functions and those who are under treatment for any thyroid related disorder were excluded from the study. Research protocol was approved by the Institutional Ethics Committee. Informed consent was obtained from all the study participants.

In addition to the basic demographic data; information on previous history of diabetes mellitus, hypertension, and treatment for dyslipidemia was collected. Complete physical examination including vitals and anthropometric parameters was carried out. WC was measured at the level of umbilicus during standing. Results of lab investigations of fasting lipid profile, fasting blood sugar (FBS), hemoglobin A1c, serum TSH, T3, and T4 were collected. Blood samples were obtained after $12 \mathrm{hrs}$ of fasting. Low-density lipoprotein (LDL) was determined by using Fried Wald formula ( $\mathrm{LDL}=\mathrm{TC}-\mathrm{HDL}-\mathrm{TG} / 5)$. Serum $\mathrm{TSH}$, serum T3, and serum $\mathrm{T} 4$ measurement were done by using Cobas e 411 device by using electrochemiluminescence immunoassay. The normal reference range of TSH was 0.42-4.2 m IU/1, of serum T3 was 1.3-3.1 ng/dl, and serum T4 was $60-180 \mathrm{nmol} / 1$. The diagnosis of hypothyroidism was made 
based on the elevated TSH level and decreased thyroid hormone level (serum T3/T4). The diagnosis of SCH was made based on elevated serum TSH level and normal thyroid hormone level. High triglyceride (TG) was considered with TG level of $>150 \mathrm{mg} / \mathrm{dl}$ or specific treatment for this and low HDL cholesterol was considered with HDL $<40 \mathrm{mg} / \mathrm{dl}$ in males and $<50 \mathrm{mg} / \mathrm{dl}$ in females, or specific treatment for this lipid abnormality. Primary outcome was to study the association between SCH and MetS. Secondary outcomes were to study the association of $\mathrm{SCH}$ with individual components of MetS (central obesity, systolic blood pressure (BP), diastolic BP, FBS, low HDL, and high TG) and association of SCH with LDL, total cholesterol, and gender. Statistical analysis was done by using SPSS sav software packages. Chi-square test was used for the comparison of qualitative data. A $p<0.05$ was considered significant.

\section{RESULTS}

MetS case group consisted of 60 participants (mean age 47.72); of them, 34 were male and 26 were female. Among 120 controls (mean age 47.61); 56 were males and 64 were females. Total number of cases with hypothyroidism was 10 ; of which $2(3.33 \%)$ were in MetS group and $8(6.66 \%)$ were in control group. This was statistically not significant $(\mathrm{p}=0.5)$

Fifty two cases of $\mathrm{SCH}$ were there among 180 study participants with prevalence of $28.9 \%$. In the MetS group, prevalence of $\mathrm{SCH}$ was $58.33 \%$ ( 35 out of 60 participants with MetS). In the control group, prevalence of $\mathrm{SCH}$ was $14.16 \%$ (17 out of 120 participants). This difference was statistically significant $(\mathrm{p}<0.001)$, suggestive of strong association between $\mathrm{SCH}$ and MetS.

When we studied the association between $\mathrm{SCH}$ and individual components of MetS, significant association was found between $\mathrm{SCH}$ and diastolic BP(Table 1).

Table-1 : Study of association between diastolic BP and SCH \begin{tabular}{|l|l|l|l|}
\hline Diastolic Blood Pressure & Subclinical hypothyroidism & Total & $\mathrm{P}$ \\
\hline
\end{tabular}

\begin{tabular}{|c|c|c|c|}
\hline \multirow[t]{2}{*}{$(\mathrm{mmHg})$} & \multicolumn{2}{|c|}{ (SCH) } & \\
\hline & Absent & Present & \\
\hline$<80$ & 57 & 14 & 71 \\
\hline $80-89$ & 44 & 20 & 64 \\
\hline 90-99 & 22 & 18 & 40 \\
\hline$>100$ & 5 & 0 & 5 \\
\hline Total & 128 & 52 & 180 \\
\hline
\end{tabular}

Significant association was also found between $\mathrm{SCH}$ and central obesity (Table 2)

There was no association between $\mathrm{SCH}$ and systolic blood pressure (Table 3)

Of 52 cases with SCH, 18 had low HDL against 34 of having normal or high HDL. This correlation was statistically not significant $(\mathrm{p}=0.72)$. Ten cases among SCH were having high TG, whereas 42 were having normal TG. This was statistically not significant $(\mathrm{p}=0.69)$.

Of 52 cases with SCH, 28 were having FBS $\geq 100 \mathrm{mg} / \mathrm{dl}$ and 24 having FBS $<100 \mathrm{mg} / \mathrm{dl}$. This association was also statistically not significant $(\mathrm{p}=0.19)$. We also compared the association of $\mathrm{SCH}$ with gender, $\mathrm{LDL}$, and total cholesterol. Of 52 cases with SCH, 26 were males and 26 were females. There was no association between $\mathrm{SCH}$ and gender $(\mathrm{p}=0.5)$. There was no association between $\mathrm{SCH}$ with $\mathrm{LDL}$ and total cholesterol (Table 4).

Association of gender with SCH in MetS group was also studied. Although association was statistically not significant, positive trend toward female gender was observed (Table 5).

Table - 2 : Study of association between central obesity and SCH

\begin{tabular}{|c|c|c|c|c|}
\hline Central Obesity & \multicolumn{2}{|c|}{$\begin{array}{c}\text { Subclinical hypothyroidism } \\
\text { (SCH) }\end{array}$} & Total & $\begin{array}{c}\text { P } \\
\text { value }\end{array}$ \\
\cline { 2 - 4 } & Absent & Present & & \\
\hline Absent & 48 & 8 & 56 & 0.004 \\
\hline Present & 80 & 44 & 124 & \\
\hline Total & 128 & 52 & 180 & \\
\hline
\end{tabular}

Table - 3 : Study of association between systolic BP and SCH

\begin{tabular}{|c|c|c|c|c|}
\hline $\begin{array}{c}\text { Systolic Blood } \\
\text { Pressure (mmHg) }\end{array}$ & \multicolumn{2}{|c|}{$\begin{array}{c}\text { Subclinical hypothyroidism } \\
\text { (SCH) }\end{array}$} & Total & $\begin{array}{c}\text { P } \\
\text { value }\end{array}$ \\
\cline { 2 - 3 } & Absent & Present & & \\
\hline$<120$ & 51 & 13 & 64 & 0.19 \\
\hline $120-139$ & 50 & 23 & 73 & \\
\hline $140-159$ & 21 & 14 & 35 & \\
\hline$\geq 160$ & 6 & 2 & 8 & \\
\hline Total & 128 & 52 & 180 & \\
\hline
\end{tabular}

Table -4 : Study of association between SCH and LDL and with total Cholesterol

\begin{tabular}{|c|c|c|c|c|}
\hline $\begin{array}{c}\text { Total Cholesterol } \\
\text { and LDL }\end{array}$ & SCH & N=180 & $\begin{array}{c}\text { Mean } \pm \text { SD } \\
(\mathrm{mg} / \mathrm{dl})\end{array}$ & P value \\
\hline Total cholesterol & Yes & 52 & $182.85 \pm 35.61$ & 0.71 \\
& No & 128 & $180.63 \pm 38.12$ & \\
\hline LDL & Yes & 52 & $111.23 \pm 32.45$ & 0.48 \\
& No & 128 & $107.44 \pm 32.97$ & \\
\hline
\end{tabular}

Table -5 : Study of association between $\mathrm{SCH}$ and gender among MetS cases group

\begin{tabular}{|l|c|c|c|c|}
\hline \multirow{2}{*}{ Gender } & \multicolumn{2}{|c|}{ Subclinical hypothyroidism $(\mathrm{SCH})$} & Total & $\begin{array}{c}\mathrm{P} \\
\text { value }\end{array}$ \\
\cline { 2 - 5 } & No & Yes & & 0.43 \\
\hline Male & 9 & 17 & 26 & 0.43 \\
\hline Female & 16 & 18 & 34 & \\
\hline Total & 25 & 35 & 60 & \\
\hline
\end{tabular}

\section{DISCUSSION}

Most important observation of our study was significant association between $\mathrm{SCH}$ and MetS. Insulin resistance and low-grade inflammation play a very important role in pathogenesis of MetS. Studies have shown the association of $\mathrm{SCH}$ with insulin resistance, with inflammation, and with individual components of MetS; hence, there is a possibility of SCH being associated with MetS also. Same was demonstrated in our study. Few other studies have also demonstrated similar association. Mechanisms behind this association are yet unclear. In study by Hamdyet al., association of SCH with MetS was observed. Positive correlation of TSH with insulin resistance was also observed in this study. Authors described both $\mathrm{SCH}$ and MetS possibly having common soil of origin, i.e., cytokines and common end points, i.e., increased CV morbidity and mortality; chances of association was there. Uzunluluet al. also observed similar association and kept possible reason being underlying inflammation responsible for both the conditions. Chughet al. demonstrated this association and explored the possibility of thyroid receptor resistance akin to insulin resistance in MetS. Raised TSH thus could be a metabolic consequence of MetS rather than a state of SCH. The stimulus for rise in TSH could also be due to hormones secreted by adipose tissue. Hence, there is a possibility of SCH being improved only or largely with life style modifications; those are recommended for the management of MetS rather than prescribing thyroid hormone supplements. Waringet al. did prospective cohort study of 2119 participants and followed up them for 6 years. They observed the association of $\mathrm{SCH}$ with prevalence but not with the incidence of MetS. Posadas-Romero et al. demonstrated fatty liver being the reason behind association between $\mathrm{SCH}$ and MetS in their study.

On the other side, few studies have not observed this association. Wang et al. did cross-sectional study of 9055 healthy participants and did not find statistically significant association between SCH and MetS. Authors explored the possibility of SCH being part of physiological aging process rather than having pathological state. Garduño-Garcia et al. in their study also did not find meaningful association. Authors raised the possibility of confounding effect of obesity in both cases and controls.

Role of anti-Thyroid peroxidise antibody (TPO) antibodies in this association is also not clear from the available literature. While autoimmunity is considered one of most common etiologies of hypothyroidism as well as $\mathrm{SCH}$; its role in cases of SCH with MetS is not clear. Collet et al. observed the association of $\mathrm{SCH}$ with increased coronary heart disease was not affected by the presence of anti-TPO in patients with $\mathrm{SCH}$. Haket al. also observed similar findings [4]. In study by Chugh, where association of $\mathrm{SCH}$ with MetS was observed; all study participants were anti-TPO negative.

Different observations and possible mechanisms explored in these 
studies suggest complex yet not completely identified relationship between SCH and MetS (Fig. 1).

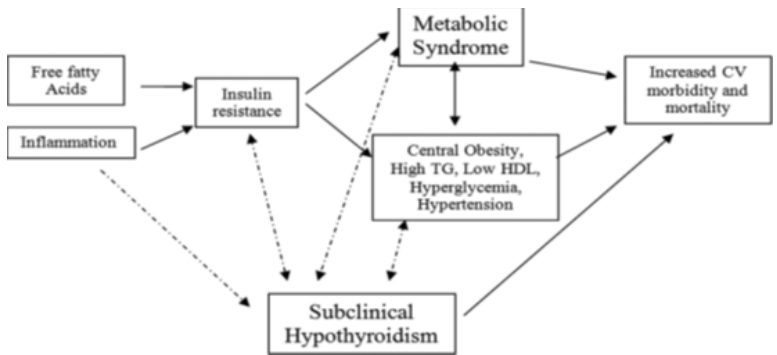

Fig. 2: Complex relationship among inflammation, insulin resistance, metabolic syndrome and its individual components and cardio-vascular morbidity

Etiopathogenesis of $\mathrm{SCH}$; its relation with autoimmunity and inflammation and role of metabolic abnormalities in it has also remained unclear. While $\mathrm{SCH}$ has been found to be responsible in pathogenesis of components of MetS; there is also a possibility that MetS contributes in pathogenesis of SCH through insulin resistance. Variability in results of studies on the association of $\mathrm{SCH}$ with MetS may partly be explained by different study population, sample size, and different cut-off used to identify SCH

In our study, $28.9 \%$ prevalence of $\mathrm{SCH}$ was observed which was high. Various studies and literature have observed and described different prevalence of SCH from $4 \%$ to $22 \%$. We had recruited participants coming for voluntary health check-up program; they were probably from upper middle to higher socioeconomic class. It is possible that factors like inflammation and insulin resistance, responsible to develop MetS were high in our study population; might be responsible to have higher prevalence of $\mathrm{SCH}$ in our study group. Moreover, early detection of $\mathrm{SCH}$, in otherwise healthy individuals who had volunteered for health check-up, might also have influenced the prevalence in our study population.

Our study also found the association of $\mathrm{SCH}$ with central obesity. We had used IDF criteria for diagnosing MetS, which is more relevant for the South Asian population. In IDF criteria, central obesity is essential criterion and any two of the remaining fours' presence is required for diagnosis of MetS. Hence, all our MetS cases were having central obesity. According to the National Cholesterol Education Program, Adult Treatment Panel III criteria; obesity is only one of the five criteria used. Moreover, similar to complex association of SCH with MetS; it is possible that unidentified relationship might be existing among inflammation, free fatty acids, adipocyte, leptin, and TSH receptor expression over adipocytes. Few other studies have shown the association of SCH and thyroid hormones with obesity [14,18,25]. Knudsen et al. explored the possibility of leptin produced by adipocytes playing important influences on central regulation of thyroid function through stimulation of thyrotropin-releasing hormone.

We found the association of SCH with diastolic BP. Effect of thyroid hormones over blood pressure is well known. Increased peripheral vascular resistance is one of the various established mechanisms for hypertension in patients with hypothyroidism. It is possible that similarly increased resistance may develop early in the state of SCH even before overt hypothyroidism develops. Various studies have also shown the association of thyroid hormones and $\mathrm{SCH}$ with hypertension

We did not find statistically significant association between $\mathrm{SCH}$ and other components of MetS, namely low HDL, high TG, and hyperglycemia. We also did not find association between $\mathrm{SCH}$ and total cholesterol as well as LDL. Various other studies have found positive association between $\mathrm{SCH}$ and these components of MetS. Nakajima et al. found a strong association between SCH and LDL as well as high TG. Authors concluded that SCH may affect serum triglyceride levels and be a risk factor for MetS. Lee et al. observed TSH showing significantly positive correlations with serum total cholesterol, TG, and LDL cholesterol regardless of sex, age, season, obesity, or menopausal status. On the other side, there are studies observing no association between $\mathrm{SCH}$ and these components of MetS. Khan et al. from Bangladesh observed no significant association among different parameters of MetS with SCH; however, when they constitute MetS; there was a significant association between MetS and $\mathrm{SCH}$. This was similar to the observations of our study. Uzunluluet al. also observed similar findings in their study. Pearce concluded in her study on update in lipid alterations in SCH that HDL-C and lipoprotein (a) levels are not altered in $\mathrm{SCH}$ patients; although smoking and insulin resistance may modify the effects of $\mathrm{SCH}$ on serum lipid values.

Variable results in these different studies may be partly because of different study designs, population characteristics, and sample size. Possibly complex yet unclear relations exist among thyroid hormones, inflammation, fatty acids, adipocytes, and lipid metabolism.

We did not observe the association of $\mathrm{SCH}$ with gender. On the other side, various studies published so far have observed positive association between SCH and female gender. Lack of gender association in our study may be because of small sample size selected from candidates coming for voluntary health check-ups only rather than general population as well as absence of sex matching between case and control group. We also studied the association of gender with $\mathrm{SCH}$ in MetS group. As shown above in Table 5, although it was statistically non-significant; positive trend toward female gender was observed. This implies in patient with MetS, female gender is more likely to have occurrence of $\mathrm{SCH}$ than males. Nonetheless, study with large samples will give better clarity on this association

Considering very small number of hypothyroid cases in our study; we did not analyze its association with MetS components.

There were certain limitations also of our study. It was cross-sectional study; so in spite of association, cause-effect relationship is not known. Sample size was relatively small compared to large sample size in various other studies. We used serum $\mathrm{T} 3$ and $\mathrm{T} 4$ to define $\mathrm{SCH}$ rather than Free T3 and Free T4, which are more specific markers. Hypothyroid cases were not excluded from case and controls. We did not include the assessment of C-reactive protein or any other markers of inflammation, thyroid autoantibodies as well as the markers of insulin resistance in our study. Inspite of all these, our study gives another evidence of positive association between $\mathrm{SCH}$ and MetS. As MetS is already known to be associated with various other metabolic abnormalities such as hyperuricemia, urinary micro-albuminemia, and non-alcoholic steato-hepatitis; its association with thyroid dysfunction may be possible. Growing incidence of life style related factors in genesis of MetS, $\mathrm{SCH}$, and other metabolic abnormalities through insulin resistance and other mechanisms is a pointer to the need of routine screening of thyroid function test in patients with MetS.

\section{CONCLUSION}

We observed high prevalence of $\mathrm{SCH}$ in study population. There was a strong association between SCH and MetS. We observed positive association between $\mathrm{SCH}$ and diastolic blood pressure and with obesity but not with other components of MetS as well as not with total cholesterol and LDL. Further studies exploring the relationships among $\mathrm{SCH}$, inflammation, insulin resistance, obesity, dyslipidemia as well as other components of MetS are required for establishing these relationships. Routine screening for $\mathrm{SCH}$ in patients with MetS and vice versa can be helpful in estimating the magnitude of overlap between two conditions, help in early detection and prompt intervention of any of the two conditions, so as to design the holistic strategies of management.

\section{REFERENCES}

Asranna A, Taneja RS, Kulshreshta B. Dyslipidemia in subclinical hypothyroidism and the effect of thyroxine on lipid profile. Indian J EndocrinolMetab 2012;16Suppl2:S347-9.

Cheserek MJ, Wu G, Shen L, Shi Y, Le G. Evaluation of the relationship between subclinical hypothyroidism and metabolic syndrome components among workers. Int J Occup Med Environ Health 2014:27(2):175-87.

Collet TH, Bauer DC, Cappola AR, Asvold BO, Weiler S, Vittinghoff E, et al. Thyroid antibody status, subclinical hypothyroidism, and the risk of coronary heart disease: An antibody status, subclinical hypothyroidism, and the risk of coronary heart diseas
individual participant data analysis. J ClinEndocrinolMetab 2014;99(9):3353-62.

4. Eckel R. The metabolic syndrome. In: Longo DL, Kasper DL, Jameson JL, Fauci AS Hauser SL, Loscalzo J, editors. Harrison's Principles of Internal Medicine. 18th ed. USA: The McGraw-Hill; 2012. p. 1992-7.

. Gencer B, Collet TH, Virgini V, Bauer DC, Gussekloo J, Cappola AR, et al. Subclinica thyroid dysfunction and the risk of heart failure events: An individual participant data analysis from 6 prospective cohorts. Circulation 2012;126(9):1040-9.

6. Hak AE, Pols HA, Visser TJ, Drexhage HA, Hofman A, Witteman JC. Subclinical hypothyridism is an in hypothyordis (a) Hamdy N, Adly N, Bakr Y, Salem A, Aty SA. Association between subclini hypothyroidism and metabolic syndrome. Int J Adv Res (Indore) 2014;2 (6):213-26

8. Klein I. Endocrine disorders and cardiovascular disease. In: Mann DL, Zipes DP, Libby P, Bonow RO, editors. Braun Wald's Heart Disease: A Textbook of Cardiovascular 
Medicine. 10th ed. Philadelphia, PA: Saunders, Elsevier; 2015.p. 1793-808

9. Rodondi N, Bauer DC, Cappola AR, Cornuz J, Robbins J, Fried LP, et al. Subclinical thyroid dysfunction, cardiac function, and the risk of heart failure. The cardiovascular health study. JAm CollCardiol 2008;52(14):1152-9.

10. Rodondi N, den Elzen WP, Bauer DC, Cappola AR, Razvi S, Walsh JP, et al. Subclinical hypothyroidism and the risk of coronary heart disease and mortality. JAMA 2010;304(12):1365-74

11. Shantha GP, Kumar AA, Jeyachandran V, Rajamanickam D, Rajkumar K, Salim S, et al. Association between primary hypothyroidism and metabolic syndrome and the role of $\mathrm{C}$ reactive protein: A cross-sectional study from South India. Thyroid Res 2009;2(1):2.

12. Tseng FY, Lin WY, Lin CC, Lee LT, Li TC, Sung PK, et al. Subclinical hypothyroidism is associated with increased risk for all-cause and cardiovascular mortality in adults. J Am CollCardiol 2012;60(8):730-7.

13. Uzunlulu M, Yorulmaz E, Oguz A. Prevalence of subclinical hypothyroidism in patients with metabolic syndrome. Endocr J 2007;54(1):71-6.

14. Walsh JP, Bremner AP, Bulsara MK, O'Leary P, Leedman PJ, Feddema P, et al. Subclinical thyroid dysfunction as a risk factor for cardiovascular disease. Arch Intern Med 2005;165(21):2467-72.

15. Waring AC, Rodondi N, Harrison S, Kanaya AM, Simonsick EM, Miljkovic I, et al. Thyroid function and prevalent and incident metabolic syndrome in older adults: The health, ageing and body composition study. ClinEndocrinol (Oxf) 2012;76(6):911-8. 